source of income for physical societies. Given the present trend to "farm out", it is perhaps not even clear that we should try to expand in this area. Nevertheless, much more can be done in participating at the editorial level in existing and future physics journals.

\section{Where to Act}

The EPS is a society of societies as well as a society of members. Seen from the individual's point of view, this is often not very satisfactory and the question of the two separate memberships which it implies has been repeatedly addressed. Questions also repeatedly come from both components of our dual structure. Some national societies would like to consider the EPS as a federation of societies, with membership of a national society coming first and implying direct membership in EPS.

However, some Divisions which organize very successful EPS conferences and workshops are annoyed to see that only a few participants are IOM's. Most participants appear satisfied with membership in a national society, or, actually, with no membership at all. Special fees have, as we saw, a declining incentive value: there is no point playing too much on them. The Division Boards would like to see only one kind of membership, but which would then be an EPS one to start with, since it would be linked to a specialized Division activity in the first place. The hope is that a sizable increase in EPS membership could then snowball. From this point of view, national societies would then appear as "national groups" within the wider structure provided by EPS.

The question is difficult since the unique membership solution appears quite different when approached from one or the other of the two components of our dual structure. But they both raise it so the question has definitely to be addressed. There is clearly a mandate from Council so it will be the main item on the agenda of the Executive Committee. It is our hope to approach the national societies and the Divisions with proposals in time for a discussion at Council, in Athens, next March.

The EPS should also provide closer links with physics in the world at large. The Society should, in particular, have stronger specific and privileged links with the American Physical Society and with the newly created Association of Asian Pacific Physical Societies. These links, especially with the former, would become more lively if they directly involved the Divisions. The aim then would be to better coordinate the organization of conferences and to run topical joint workshops. Much remains to be done. The interest expressed by Council was clear. It is our hope to implement initiatives as quickly as possible. Associations with other large physical societies in the world, who consider the EPS as their natural partner in Europe, should be a further incentive to join the EPS once their outcome has become lively and visible to all.

We should develop our links with our Associate Members into an active partnership. They represent a most valuable connection with applied research and industry. They certainly represent part of the solution to our financial problems.

As Benjamin Franklin wrote in The Way of Wealth, reprinted 400 times: "There is no gains without pains. If we are industrious we shall never starve; at the working man's house, hunger looks in but does not enter, nor will the bailiff or the constable enter, for industry pays debts while despair increases them". Let us work together for a brilliant 25th Anniversary of EPS in 1993.

\title{
EUROPEAN RESEARCH CONFERENCES A Pragmatic Approach
}

The European Science Foundation (ESF) launched in 1990 a series of meetings called the European Research Conferences (ERC). The programme is managed by the ESF and supervised by an ESF steering committee.

The EPS as a learned society was invited by the ESF to appoint a member to the steering committee to check and guarantee the quality of ERC's in physics. All conferences covering a physics topic must be approved by a working group of EPS composed of several members of the Action Committee on Conferences.

\section{Organization of ERC's}

A Chairman responsible for the scientific programme has available about 20000 ECU to invite speakers and preferentially support the participation of younger scientists. This amount is allocated by the ESF and funded by the European Community (EC). The number of participants at an ERC should in general not exceed about 100 to guarantee lively discussion of scientific topics which are not yet ready for publication. Proceedings will therefore in general not be published.

It is intended that conferences be held as a series with an annual or biannual sequence. The Chairman of a succeeding conference should be elected early enough so that he or she can act as the Vice-Chairman of the current meeting.

ERC's should take place at locations where the participants can live together for the duration of the conference to allow for discussion outside the technical sessions. Locations will generally be proposed by the ESF steering committee based in Strasbourg, which also will be responsible for administration. Organizational arrangements are intended to ensure that the Chairman of the conference is relieved of administrative work. This implies, however, that the ESF office determines the conference fee.

Seed money from the ESF in addition to the usual conference fees was used to start the ERC's in 1990 and 1991. It was expected that funding support from the EC would start in 1991 but the necessary decisions have been postponed to September 1991. This may cause some difficulties in pursuing the published programme.

\section{Programme}

Two ERC's covering physics topics were held in 1990, the first year of the programme. The 1991 programme in physics was approved by the EPS Working Group in December 1990 and it comprises six conferences (see Europhysics News, Meetings Issue, March 1991).

The 1992 programme which is presently being discussed will include about eight ERC's in physics. Proposals for these conferences mostly came from EPS divisions. ERC's thus follow along the same lines as the well established Study Conferences.

\section{Further Developments}

The ERC scheme seemed almost ideal when it started, leading to the suggestion that the Europhysics Study Conferences may merge completely into the ERC's. However, in the course of establishing the ERC's and developing the rules which should guide the conferences and negotiations with the Commission of the EC (CEC), several restrictions became apparent.

EPS incorporates Divisions having research goals that are different from the pure science, such as educational development, the history of physics and scientific matters that are not strictly in physics but are nonetheless closely connected. Conferences organized by these Divisions had to be excluded from the ERC scheme because the topics did not fit into the guidelines set out by the CEC for supporting ERC's.

Furthermore, the Divisions of EPS have considerable experience in organizing conferences so in many respects they do not need the close help of the ESF. This led to serious discussions and finally to the withdrawal of one conference from the ERC schedule for 1992. Points of discussion were site selection, conference fees and, in some cases, interference in inviting speakers.

The EPS Conference Committee will thus adopt a pragmatic approach in future. If conferences can be included in the ERC scheme we shall do this wherever possible and try to obtain the financial support of ESF. In some cases, the Divisions may, however, wish to proceed as in the past and organize Study Conferences following the well established guidelines.

\section{K. Bethge}

Chairman,

EPS Action Committee on Conferences 